\title{
DISINFLATION AND \\ EXCHANGE-RATE PASS-THROUGH
}

\author{
OzGe Senay \\ Middle East Technical University
}

This paper analyzes exchange-rate dynamics following a money-based disinflation under different degrees of exchange-rate pass-through. Using a microfounded dynamic general equilibrium model with imperfect competition and nominal rigidities, it is shown that a monetary slowdown causes an appreciation of the exchange rate and a short-run fall in employment. Varying the degree of pass-through, however, significantly alters the magnitudes of these effects. As the degree of pass-through is reduced, the extent of the short-run appreciation of the exchange rate increases and the short-run impact of the disinflation on employment falls.

Keywords: Disinflation, Exchange Rates, Pass-through, New Open Economy Macroeconomics

\section{INTRODUCTION}

Disinflations are often regarded as being an important cause of recessions and other economic dislocations. One means of inflation stabilization for a country operating in a floating-exchange-rate regime is a money-based disinflation, that is, a policy based on a reduction in the rate of growth of the money supply. In such cases, an important factor that can lead to dislocations is the movement of the exchange rate triggered by the disinflation policy. Previous literature, for instance Betts and Devereux $(1996,2000)$, has shown that the degree of exchange rate pass-through to prices has important implications for how the exchange rate responds to changes in monetary policy. Extensive evidence, presented for instance by Engel (1999) and Goldberg and Knetter (1997), has shown that the presence of incomplete exchange-rate pass-through is an empirically relevant feature of most economies. It therefore follows that, in analyzing the real effects of a money-based disinflation policy, it is important to understand the implications of incomplete pass-through for the adjustment process following a monetary slowdown. The objective of this paper is to analyze the implications of different degrees of exchange-rate pass-through for the effects of a money-based disinflation.

Earlier literature on disinflation, for instance Buiter and Miller (1982, 1985), has found that a money-based disinflation generates a strong appreciation of the

I am grateful for many useful and detailed comments and suggestions from two anonymous referees, which have significantly improved the paper, and from Alan Sutherland and Peter N. Smith on an earlier version of this paper. Address correspondence to: Department of Economics, Middle East Technical University, Inonu Bulvari, Ankara 06531, Turkey; e-mail: osenay@metu.edu.tr. 
exchange rate in the short run, which overshoots the required long-run adjustment. This strong appreciation of the domestic currency is found to lead to a severe recession in the domestic economy in the short run. Buiter and Miller (1981, 1983) emphasize this overshooting of the exchange rate in their interpretation of the Thatcher disinflation that took place in the United Kingdom in the early 1980s.

This earlier literature on the real effects of disinflation in open economies, however, was based on a variant of the Dornbusch (1976) model. The current paper, on the other hand, follows the more recent open-economy literature by adopting a microfounded approach to understanding the effects of monetary policy. The model used in this paper is a modified version of Obstfeld and Rogoff (1995) and is essentially a general equilibrium model combining nominal rigidities [in the form of Calvo (1983)-style price contracts] and imperfect competition into an intertemporal optimizing framework. ${ }^{1}$ This model is used to investigate the implications of incomplete exchange rate pass-through for the effects of a monetary slowdown.

The paper proceeds as follows: Section 2 outlines the model, section 3 presents the numerical simulation results, and section 4 concludes.

\section{THE MODEL}

There are two countries, home and foreign. Foreign country variables are denoted with an asterisk. The two countries are inhabited by a continuum of infinitely lived individual consumers and producers. Households consume a group of differentiated, perishable goods of total measure unity. These goods, produced by firms, are indexed by $z$ on the unit interval. Home country firms produce fraction $n$ goods and foreign firms produce $1-n$ goods. Thus $n$ is a measure of the size of the home country. In the simulations reported below $n$ will be set at a value close to zero, so the home country can be regarded as a small open economy. ${ }^{2}$

Incomplete exchange-rate pass-through is represented by the presence of some firms that set prices in the local currency of the buyer, that is, engage in local currency pricing (LCP). This means that the domestic price of imports is to some extent fixed with respect to the fluctuations of the exchange rate; that is, exchange rate pass-through is incomplete. A fraction $s$ of firms in both countries are assumed to engage in local currency pricing. These LCP firms choose prices separately for the home and foreign market, denoted in the local currency of the consumer in each case. The possibility of individuals arbitraging away price differentials between the two countries is ruled out. The remaining $1-s$ of firms in both countries set prices in their own currency, that is, engage in producer currency pricing (PCP). These PCP firms set a single price denoted in the currency of the producer. Regarding the prices of PCP goods, there is complete exchange-rate pass-through. The parameter $s$, the share of LCP firms, is a measure of the degree of aggregate incomplete pass-through in the world economy. 


\subsection{Households}

The representative household in the home country maximizes a utility function that depends on consumption $C$, real money balances $M / P$, and labor supplied $N$,

$$
U_{t}=\sum_{\tau=t}^{\infty} \beta^{\tau-t}\left[\frac{\sigma}{\sigma-1} C_{\tau}^{\frac{(\sigma-1)}{\sigma}}+\frac{\chi}{1-\epsilon}\left(\frac{M_{\tau}}{P_{\tau}}\right)^{1-\epsilon}-\mu^{-1} N_{\tau}^{\mu}\right],
$$

with $0<\beta<1, \sigma>0, \epsilon>0$, and $\mu \geq 1$. Letting $c(z)$ be a home household's consumption of good $z$ and $\theta$ be the elasticity of demand for consumption goods, the consumption index is $C=\left[\int_{0}^{1} c(z)^{(\theta-1) / \theta} d z\right]^{\theta /(\theta-1)}$. The consumer price index (CPI) for the home economy is denoted $P$ and is defined as

$$
\begin{aligned}
P_{t} & =\left\{\int_{0}^{n s} p_{\mathrm{L}, t}(z)^{1-\theta} d z+\int_{n s}^{n} p_{\mathrm{P}, t}(z)^{1-\theta} d z+\int_{n}^{n+(1-n) s} p_{\mathrm{L}, t}^{*}(z)^{1-\theta} d z\right. \\
& \left.+\int_{n+(1-n) s}^{1}\left[E_{t} q_{\mathrm{P}, t}^{*}(z)\right]^{1-\theta} d z\right\}^{\frac{1}{(1-\theta)}},
\end{aligned}
$$

where $p_{\mathrm{L}, t}(z)$ represents the home currency price of home-produced LCP good $z, p_{\mathrm{P}, t}(z)$ the home currency price of home-produced PCP $\operatorname{good} z, p_{\mathrm{L}, t}^{*}(z)$ the home currency price of foreign LCP good $z$, and $q_{\mathrm{P}, t}^{*}(z)$ the foreign currency price of foreign PCP good $z$. So $p$ represents home currency prices and $q$ represents foreign currency prices. Prices without asterisks are for home goods and those with asterisks are for foreign goods. Prices with the subscript L relate to LCP firms and those with the subscript P relate to PCP firms. $E_{t}$ is the exchange rate, that is, the domestic unit cost of foreign currency.

World capital markets are assumed to be perfectly integrated, so there is a single world bond market. This implies uncovered interest parity as follows:

$$
\left(1+i_{t}\right) E_{t}=\left(1+i_{t}^{*}\right) E_{t+1},
$$

where $i_{t}$ denotes the domestic nominal interest rate. Households divide their wealth holdings between bonds and domestic currency. The government in each country prints money and makes lump sum transfers $T_{t}$ and the home government budget constraint is

$$
P_{t} T_{t}=M_{t}-M_{t-1}
$$

Given the above setting for their interactions with financial markets and that households receive income from wages $w_{t} N_{t}$ and profits $\Pi_{t}$ on their ownership of domestic firms, holdings of bonds are governed by the flow budget constraint

$$
D_{t}=\left(1+i_{t-1}\right) D_{t-1}+M_{t-1}-M_{t}+w_{t} N_{t}-P_{t} C_{t}+\Pi_{t}+P_{t} T_{t},
$$

where $D$ denotes net foreign assets of the home household. Households in the home economy maximize lifetime utility (1) subject to (5) and to their given 
initial holdings of domestic currency and bonds. Optimal consumption, optimal money demand, and optimal labor supply decisions, respectively, satisfy

$$
\begin{aligned}
C_{t+1} & =C_{t}\left[\left(\beta\left(1+i_{t}\right) P_{t}\right) / P_{t+1}\right]^{\sigma} \\
M_{t} / P_{t} & =\left[\chi C_{t}^{1 / \sigma}\left(\left(1+i_{t}\right) / i_{t}\right)\right]^{1 / \epsilon} \\
N_{t}^{(\mu-1)} & =C_{t}^{-1 / \sigma} w_{t} / P_{t} .
\end{aligned}
$$

Equation (6) is the standard consumption Euler equation. The household's optimal money demand schedule is given by (7), which equates the marginal rate of substitution of consumption for real money balances to the opportunity cost of holding real balances. The household's optimal labor supply decision is shown by (8); this equates the marginal disutility of labor effort to the marginal utility of the real wage. Labor markets are assumed to be segregated, with real wages determined by market clearing in each country. Note that the first-order conditions and the period budget constraint do not fully characterize the equilibrium of the household's maximization problem. Equilibrium also requires the transversality condition to hold, as follows,

$$
\lim _{T \longrightarrow \infty} R_{t, t+T}\left(\frac{D_{t+T+1}}{P_{t+T+1}}+\frac{M_{t+T}}{P_{t+T}}\right)=0,
$$

where $R_{t, t+T}=\left(1 /\left(1+\mathrm{r}_{t}\right)\right)\left(1 /\left(1+\mathrm{r}_{t+1}\right)\right) \ldots\left(1 /\left(1+\mathrm{r}_{t+T}\right)\right)$ and $\mathrm{r}_{t}$ is the real interest rate. The home household's demand for each differentiated good is $c_{t}(z)=\left[a_{t}(z) / P_{t}\right]^{-\theta} C_{t}$, where $a_{t}(z)$ can be $p_{\mathrm{L}, t}(z), p_{\mathrm{P}, t}(z), p_{\mathrm{L}, t}^{*}(z)$, or $\left[E_{t} q_{\mathrm{P}, t}^{*}(z)\right]$, depending on the type of good.

\subsection{Firms}

All firms have an identical linear production technology, $Y_{t}(z)=N_{t}(z)$, where $Y_{t}(z)$ is the total output of firm $z$ and $N_{t}(z)$ is the employment of firm $z$. Total output of a home LCP firm producing good $z$ is made up of demand from the home country, $x_{\mathrm{H}, t}$ and demand from the foreign country, $x_{\mathrm{F}, t}$ :

$$
x_{\mathrm{H}, t}(z)=\left[\frac{p_{\mathrm{L}, t}(z)}{P_{t}}\right]^{-\theta} n C_{t}, \quad x_{\mathrm{F}, t}(z)=\left[\frac{q_{\mathrm{L}, t}(z)}{P_{t}^{*}}\right]^{-\theta}(1-n) C_{t}^{*} .
$$

Total demand for a home-produced PCP good is given by

$$
y_{t}(z)=\left[\frac{p_{\mathrm{P}, t}(z)}{P_{t}}\right]^{-\theta} n C_{t}+\left[\frac{p_{\mathrm{P}, t}(z)}{P_{t}^{*} E_{t}}\right]^{-\theta}(1-n) C_{t}^{*} .
$$

Total output of a foreign LCP firm producing good $z$ is made up of demand from the home country, $x_{\mathrm{H}, t}^{*}$, and demand from the foreign country, $x_{\mathrm{F}, t}^{*}$ :

$$
x_{\mathrm{H}, t}^{*}(z)=\left[\frac{p_{\mathrm{L}, t}^{*}(z)}{P_{t}}\right]^{-\theta} n C_{t}, \quad x_{\mathrm{F}, t}^{*}(z)=\left[\frac{q_{\mathrm{L}, t}^{*}(z)}{P_{t}^{*}}\right]^{-\theta}(1-n) C_{t}^{*} .
$$


Total demand for a foreign-produced PCP good is given by

$$
y_{t}^{*}(z)=\left[\frac{E_{t} q_{\mathrm{P}, t}^{*}(z)}{P_{t}}\right]^{-\theta} n C_{t}+\left[\frac{q_{\mathrm{P}, t}^{*}(z)}{P_{t}^{*}}\right]^{-\theta}(1-n) C_{t}^{*}
$$

Prices are assumed to be sticky in that, within any given period, some firms cannot immediately respond to economic disturbances by changing prices. Instead, firms respond to disturbances by meeting market demand at preset prices. The specific form of sluggish price adjustment considered here is that described by Calvo (1983). The probability that a given firm changes its price in any given period is a constant, $(1-\gamma)$. Prices of LCP goods are preset in the buyer's currency, so the foreign currency price of the seller's good will not change with movements in exchange rates. Foreign currency prices of PCP goods, set in the producer's own currency, change with movements in the exchange rate.

LCP firms' maximization problem. Period $t$ profits for a home LCP firm $z$, which sets its price in period $t$, are defined as

$$
\begin{aligned}
& \Pi_{t}^{\mathrm{L}}(z)=\left[\frac{p_{\mathrm{L}, t}^{\mathrm{N}}(z)}{P_{t}}\right]^{-\theta} n C_{t}\left[p_{\mathrm{L}, t}^{\mathrm{N}}(z)-w_{t}\right] \\
& +\left[\frac{q_{\mathrm{L}, t}^{\mathrm{N}}(z)}{P_{t}^{*}}\right]^{-\theta}(1-n) C_{t}^{*}\left[E_{t} q_{\mathrm{L}, t}^{\mathrm{N}}(z)-w_{t}\right] .
\end{aligned}
$$

The first part of equation (13) represents profits from home sales of good $z$ and the second, profits from sales of the good to the foreign country. Prices, $p_{\mathrm{L}, t}^{\mathrm{N}}(z)$ and $q_{\mathrm{L}, t}^{\mathrm{N}}(z)$, with the superscript $\mathrm{N}$ indicate the new price set in period $t$ by those producers who have the opportunity to reset their prices.

The presence of nominal rigidities, in the form of Calvo price inertia, introduces a dynamic dimension into the firm's optimization problem, in the sense that prices chosen by the firm in one period may still be in force in further periods and thus have an influence on the profits of the firm in the future. In this case, the firm must maximize the discounted value of all its current and future profits, taking into account the probability of the current price being in force. This is done by weighting each future period by the probability the firm will leave its price unchanged, namely $\gamma$. In this case an individual home LCP firm $z$ maximizes

$$
\begin{aligned}
& V_{t}^{\mathrm{L}}(z)=\sum_{\tau=t}^{\infty} \gamma^{\tau-t} R_{t, \tau} \frac{1}{P_{\tau}}\left[\frac{p_{\mathrm{L}, t}^{\mathrm{N}}(z)}{P_{\tau}}\right]^{-\theta} n C_{\tau}\left[p_{\mathrm{L}, t}^{\mathrm{N}}(z)-w_{\tau}\right] \\
& +\sum_{\tau=t}^{\infty} \gamma^{\tau-t} R_{t, \tau} \frac{1}{P_{\tau}}\left[\frac{q_{\mathrm{L}, t}^{\mathrm{N}}(z)}{P_{\tau}^{*}}\right]^{-\theta}(1-n) C_{\tau}^{*}\left[E_{\tau} q_{\mathrm{L}, t}^{\mathrm{N}}(z)-w_{\tau}\right] .
\end{aligned}
$$


Given the Calvo structure, the first-order conditions of the home LCP firm $z$ are

$$
\begin{gathered}
p_{\mathrm{L}, t}^{\mathrm{N}}(z)(\theta-1) \sum_{\tau=t}^{\infty} \gamma^{\tau-t} R_{t, \tau} \frac{C_{\tau}}{P_{\tau}^{1-\theta}}=\theta \sum_{\tau=t}^{\infty} \gamma^{\tau-t} R_{t, \tau} \frac{C_{\tau}}{P_{\tau}^{1-\theta}} w_{\tau} \\
q_{\mathrm{L}, t}^{\mathrm{N}}(z)(\theta-1) \sum_{\tau=t}^{\infty} \gamma^{\tau-t} R_{t, \tau} \frac{C_{\tau}^{*}}{P_{\tau} P_{\tau}^{*-\theta}} E_{t}=\theta \sum_{\tau=t}^{\infty} \gamma^{\tau-t} R_{t, \tau} \frac{C_{\tau}^{*}}{P_{\tau} P_{\tau}^{*-\theta}} w_{\tau} .
\end{gathered}
$$

The structure of pricing behavior by firms implies that firms that do change their price in period $t$ will all change it to the same levels, $p_{\mathrm{L}, t}^{\mathrm{N}}$ and $q_{\mathrm{L}, t}^{\mathrm{N}}$, in domestic and foreign currency respectively. The number of firms that last set their prices in period $t-1$, given by $(1-\gamma) \gamma$, again will have set it at the same levels $p_{\mathrm{L}, t-1}^{\mathrm{N}}$ and $q_{\mathrm{L}, t-1}^{\mathrm{N}}$.

PCP firms' maximization problem. PCP firms determine a single price for their good, to be charged both in the home and foreign country. In the absence of nominal rigidities, home PCP firm $z$ maximizes

$$
\Pi_{t}^{\mathrm{P}}(z)=\left[\frac{p_{\mathrm{P}, t}^{\mathrm{N}}(z)}{P_{t}}\right]^{-\theta} n C_{t}\left[p_{\mathrm{P}, t}^{\mathrm{N}}(z)-w_{t}\right]+\left[\frac{p_{\mathrm{P}, t}^{\mathrm{N}}(z)}{P_{t}^{*} E_{t}}\right]^{-\theta}(1-n) C_{t}^{*}\left[p_{\mathrm{P}, t}^{\mathrm{N}}(z)-w_{t}\right]
$$

The first part of (17) represents profits from home sales of good $z$ and the second profits from sales of the good in the foreign country. Introducing nominal rigidities in the form of Calvo price inertia leads to the following profit equation, the PCP counterpart of equation (14):

$$
\begin{aligned}
& V_{t}^{\mathrm{P}}(z)=\sum_{\tau=t}^{\infty} \gamma^{\tau-t} R_{t, \tau} \frac{1}{P_{\tau}}\left[\frac{p_{\mathrm{P}, t}^{\mathrm{N}}(z)}{P_{\tau}}\right]^{-\theta} n C_{\tau}\left[p_{\mathrm{P}, t}^{\mathrm{N}}(z)-w_{\tau}\right] \\
& +\sum_{\tau=t}^{\infty} \gamma^{\tau-t} R_{t, \tau} \frac{1}{P_{\tau}}\left[\frac{p_{\mathrm{P}, t}^{\mathrm{N}}(z)}{P_{\tau}^{*} E_{\tau}}\right]^{-\theta}(1-n) C_{\tau}^{*}\left[p_{\mathrm{P}, t}^{\mathrm{N}}(z)-w_{\tau}\right] .
\end{aligned}
$$

Because PCP firms set a single price, the first-order condition of PCP firm $z$ that leads to a single price-setting condition for $p_{\mathrm{P}, t}^{\mathrm{N}}(z)$ is

$$
\begin{gathered}
p_{\mathrm{P}, t}^{\mathrm{N}}(z)(\theta-1) \sum_{\tau=t}^{\infty} \gamma^{\tau-t} R_{t, \tau}\left(\frac{n C_{\tau}}{P_{\tau}^{1-\theta}}+\frac{(1-n) C_{\tau}^{*}}{P_{\tau}\left(P_{\tau}^{*} E_{\tau}\right)^{-\theta}}\right) \\
=\theta \sum_{\tau=t}^{\infty} \gamma^{\tau-t} R_{t, \tau}\left(\frac{n C_{\tau}}{P_{\tau}^{1-\theta}}+\frac{(1-n) C_{\tau}^{*}}{P_{\tau}\left(P_{\tau}^{*} E_{\tau}\right)^{-\theta}}\right) w_{\tau} .
\end{gathered}
$$

\subsection{Equilibrium Conditions}

Equilibrium in the world economy is a set of consumption, outputs, exchange rate, prices, and wages enabling market clearing in goods, labor, money, and bond 
markets that is, set of variables that (i) satisfy the optimal evolution of intertemporal consumption given by the Euler equation in each country, equation (6), and its foreign counterpart; (ii) clear the money market in both countries in each period, that is, equation (7) and its foreign counterpart; (iii) clear labor markets in each period, that is, satisfy equation (8) and its foreign counterpart, where total demand for home labor is given by

$$
n N_{t}=\int_{0}^{s n}\left[x_{\mathrm{H}, t}(z)+x_{\mathrm{F}, t}(z)\right] d z+\int_{s n}^{n} y_{t}(z) d z
$$

and a similar condition applies to the foreign country; (iv) satisfy conditions for optimal price setting by home firms in each time period for LCP goods, equations (15) and (16), and PCP goods, equation (19), and their foreign counterparts; (v) satisfy the flow budget constraint, equation (5), and its foreign counterpart, with present discounted values of total consumption in each country being equal to the present discounted values of total labor and profit income; (vi) satisfy the uncovered interest parity condition, equation (3); (vii) satisfy the government budget constraint, equation (4), and its foreign counterpart. A full set of equilibrium conditions is presented in Appendix A.

\subsection{The Steady State}

The policy experiment considered in this paper is one where, in the initial steady state, the home economy faces positive inflation and policymakers aim to bring inflation down through an immediate and unanticipated disinflation programme. The above-described open-economy model of staggered prices is used to analyze disinflation through a reduction in the rate of growth of the money supply, where the money supply is exogenous and the exchange rate floats and accommodates the monetary slowdown. Because no closed-form solution to the model may be obtained, the effects of disinflation are analyzed through numerical simulations of the above model in its calibrated and log-linearized form.

To linearize the system, a well-defined steady state around which to approximate is required. The results reported below are based on a steady state where all exogenous variables are constant, the rate of growth of all nominal variables is zero, and net foreign assets are zero. The steady-state values around which the system is linearized are the following:

$$
\begin{gathered}
\bar{r}=(1-\beta) / \beta \\
\bar{w} / \bar{P}=\bar{w}^{*} / \bar{P}^{*}=(\theta-1) / \theta \\
\bar{C}=\bar{N}=\bar{C}^{*}=\bar{N}^{*}=((\theta-1) / \theta)^{\frac{\sigma}{\sigma(\mu-1)+1}} \\
\bar{M} / \bar{P}=\bar{M}^{*} / \bar{P}^{*}=\left(\chi \bar{C}^{\frac{1}{\sigma}} /(1-\beta)\right)^{\frac{1}{\epsilon}}
\end{gathered}
$$


The dynamics of the calibrated and log-linearized model are analyzed in terms of deterministic solution paths in the next section. Appendix B provides a list of all the log-linearized equations of the model.

In order to simulate a disinflation it is necessary to derive starting values for variables based on an initial inflationary steady state. This requires an analysis of the effects of the initial rate of inflation, denoted $\alpha$, on steady-state values. This is most easily achieved by considering a linearized version of the model's steadystate relationships, where the linearization is based around the above-defined zero-inflation steady-state values, equations (21), (22), (23), and (24).

In the simulations shown below, $\alpha$ is set at 0.01 (i.e., $1 \%$ ). In period 0 the home economy is thus assumed to be in a steady state with $1 \%$ inflation. In period 1 the rate of home money growth is reduced to zero and held at zero thereafter. The sudden slowdown in home money growth to zero results in transitional dynamics and finally a new zero inflation long-run equilibrium. The foreign money growth rate is zero in all periods (including the initial steady state).

An inflationary steady state differs from a noninflationary steady state in four main respects. The first is that the nominal interest rate is above that in the noninflationary steady state by $\alpha$, the rate of inflation. The second important difference (which leads on from the first) is that demand for real balances is suppressed relative to the noninflationary steady state. This in turn leads to the third difference, which is that nominal goods prices are higher (relative to a given nominal money supply) than in the noninflationary steady state. Finally, the nominal exchange rate is depreciated (relative to a given nominal money supply) compared to its level in a noninflationary steady state.

\section{RESULTS}

This section presents and discusses numerical solutions of the log-linear approximation of the model.

\subsection{Complete Exchange-Rate Pass-Through}

Initially, the effects of a money-based disinflation are considered in the case where there is full exchange-rate pass-through, that is, $s=0$, so that all firms are PCP firms. Dynamic adjustment paths of home macroeconomic variables are presented in Figure 1 (the plot with squares). Each panel of the figure shows deviations from the initial inflationary steady state (except for the CPI inflation and nominal interest rate panels). The parameter values used in the simulations are $n=0.001$, $\beta=1 / 1.05, \gamma=0.66, \sigma=0.75, \mu=5, \theta=2, \epsilon=9, \chi=1 .^{3}$

The most obvious effect of a money-based disinflation with complete exchangerate pass-through $(s=0)$ is that a domestic recession immediately follows the monetary slowdown. More specifically, it is seen in Figure 1 that home employment and thus real wages, defined as the nominal wage divided by the CPI, fall in the short run. ${ }^{4}$ One of the key factors leading to the employment costs of the 

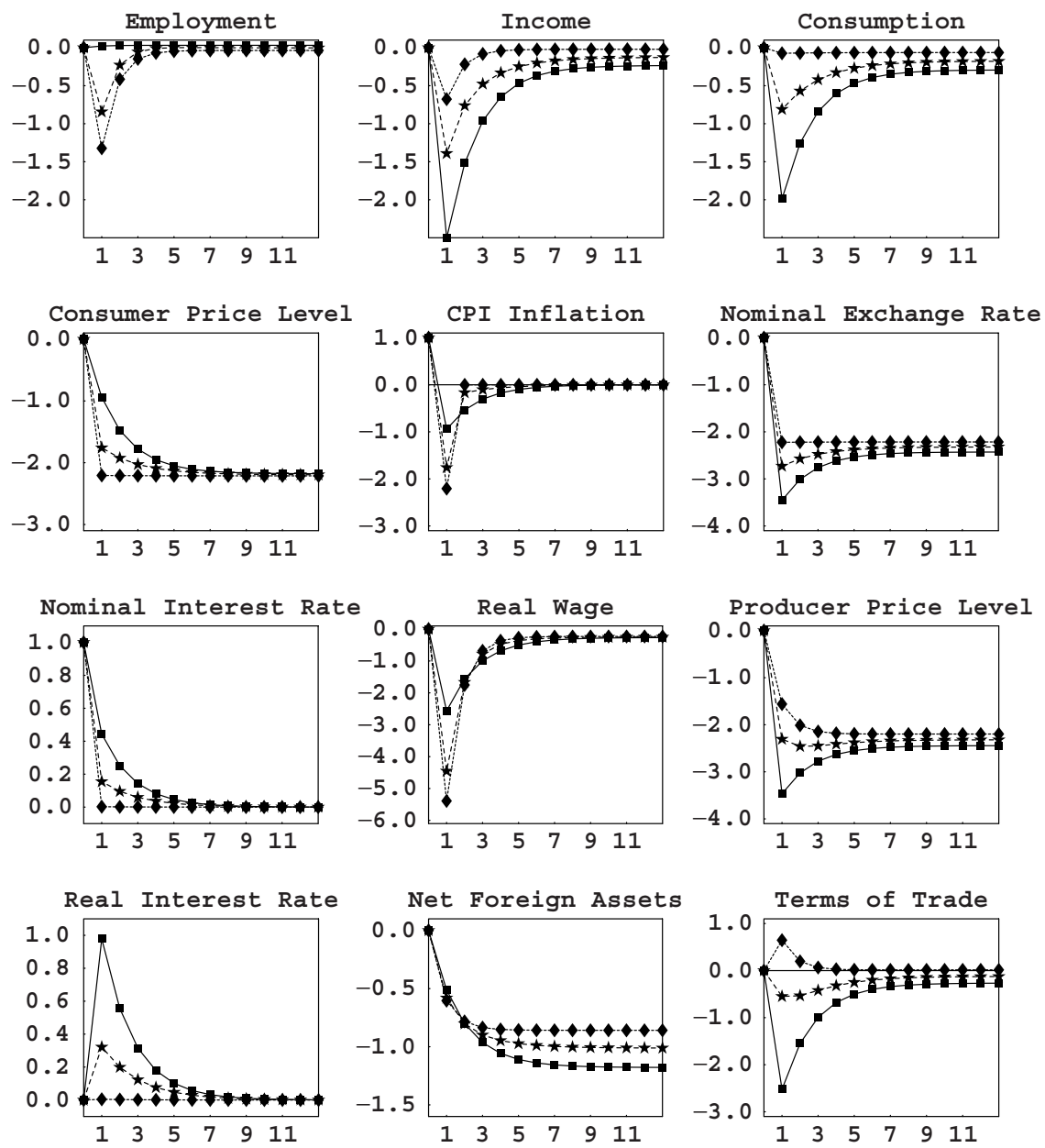

FIGURE 1. Disinflation and exchange-rate pass-through. $\mathbf{\square}, s=0 ; \star, s=0.5$; and $\bullet, s=1$.

disinflation is an appreciation of the exchange rate. The fall in employment is accompanied by a fall in home income and home consumption. The fall in income is somewhat smaller than the fall in employment because of an improvement in the terms of trade, and, due to consumption smoothing, the fall in consumption is relatively smaller than the fall in income. ${ }^{5}$ So the domestic economy runs down its stock of assets and this leads to some long-run effects (which are necessary to finance the short-run loss of domestic assets, as seen in the fall in net foreign assets).

The key mechanism that produces the real effects of money-based disinflation is the link between the nominal interest rate and the demand for real balances. A reduction in the rate of inflation implies a fall in the expected inflation rate 
and the nominal interest rate, which in turn implies an increase in the demand for real balances. Money market equilibrium necessitates a subsequent rise in real balances. In a money-based disinflation, where the nominal money supply is fixed, the required increase in real balances can only come about through a reduction in the consumer price level. An immediate downward adjustment in the consumer price level is brought about by the appreciation of the nominal exchange rate, which jumps to its new long-run steady-state level. ${ }^{6}$ Although this brings the supply and demand for real balances back into equilibrium, the consequent increase in the real terms of trade implies a fall in the demand for home goods. This fall in demand can only be reversed by a fall in the price of home-produced goods. However, producer prices are slow to adjust, because of the presence of Calvo overlapping contracts, so an extended recession (fall in employment) is required to generate a fall in the producer price level. ${ }^{7}$

It can be seen from Figure 1 that there is very little persistence in the consumer inflation rate. Inflation drops almost immediately to its new long-run equilibrium value of zero. There is, however, some persistence in the output effects of the disinflation. As explained in the previous paragraph, a recession is necessary to push the producer price level down to its new steady-state level. The fact that the producer price level is sluggish to adjust implies that employment has to remain below its steady-state value for an extended period of time.

To highlight the importance of the link between nominal interest rates and the demand for real balances in this model, simulations varying $\epsilon$, which is effectively the inverse of the interest elasticity of money demand, were carried out. These simulations (not reported) show that as the interest elasticity of money demand decreases, so do the price and output adjustments required for money market equilibrium.

The earlier literature, for example Buiter and Miller (1982, 1985), on the real effects of disinflation in open economies concluded that money-based disinflation led to a recession in the domestic economy in the short run with an appreciation of the exchange rate. It appears that these fundamental results of the earlier literature also hold true in the model of this paper with complete exchange-rate passthrough. With a monetary slowdown, there are substantial short-run output costs and disinflation does take time, with high real interest rates and some exchange rate appreciation in the short run.

Although the short-run output effects under money-based disinflation are common to the model of this paper (with complete pass-through) and the earlier literature based on variants of the Dornbusch (1976) model, there remain important differences between the results of the two types of models. One difference is the presence of long-run real effects arising from the run-down in domestic assets under money-based disinflation in the current microfounded model. The income and consumption panels in Figure 1 show that income and consumption both fall after the monetary slowdown. Due to consumption smoothing, the fall in consumption is less than the fall in income. This implies that the domestic economy is running down its stock of bond holdings to finance consumption and 
that the domestic country is facing a trade deficit. Long-run consumption in the domestic economy is lower than long-run income (as seen in Figure 1). This long-run surplus finances the short-run loss of domestic assets and the consequent interest payments on bonds held by the foreign country, as can be seen in the net foreign assets panel of Figure 1.

The second difference between the results of the current model with complete pass-through and earlier disinflation models is that, although the above results show some appreciation in the exchange rate under money-based disinflation, there is no exchange-rate overshooting, in the sense that the nominal exchange rate does not appreciate more in the short run than it does in the long run. Overshooting of this type was a key result that was emphasized by Buiter and Miller (1982).

Before turning to the analysis of the case with incomplete pass-through, it is interesting first to consider the effects of changing the degree of price inertia, that is, the effects of varying $\gamma$ (the probability that a firm will not adjust its price in any given period). Figure 2 illustrates the effects of disinflation when $\gamma$ is set at 0.5 . This implies greater price flexibility than in the benchmark case reported in Figure 1. Two main points emerge from Figure 2. One is that the size of the impact effect of the disinflation on all variables is reduced compared to the case with $\gamma=0.66$. Thus, for instance, the size of the recession following the disinflation is smaller than the benchmark case. The second difference is that the speed of transition to the new steady state is more rapid when prices are more flexible.

\subsection{Incomplete Exchange Rate Pass-Through}

This section analyzes the implications of incomplete exchange-rate pass-through on money-based disinflation. The simulation results of disinflation with different degrees of exchange-rate pass-through are also presented in Figure 1. The degree of exchange-rate pass-through is represented by $s$, the proportion of LCP firms in the world economy. Figure 1 shows results for $s=0.5$ (the plot with stars) and $s=1.0$ (the plot with diamonds), both cases representing incomplete pass-through.

Figure 1 shows that the responses of the exchange rate and many other variables are significantly different when there is incomplete pass-through. The magnitudes of the impact effects and the transitional values of all real and nominal variables to a new long-run equilibrium are significantly changed when the degree of pass-through is restricted. One of the main implications of incomplete passthrough is that the nominal exchange rate overshoots its long-run equilibrium value in response to the monetary slowdown. In fact, the amount of overshooting increases as the degree of pass-through decreases (higher values of $s$ ), as seen in the exchange-rate panel of Figure 1.

The implications of the overshooting of the exchange rate for real variables are also seen in Figure 1. The extent to which exchange-rate movements induced by a monetary slowdown lead to a decrease in demand for domestic goods depends on the degree to which exchange-rate changes are passed onto the relative price of domestic goods. If producers engage in LCP, that is, prices are fixed by contracts in 

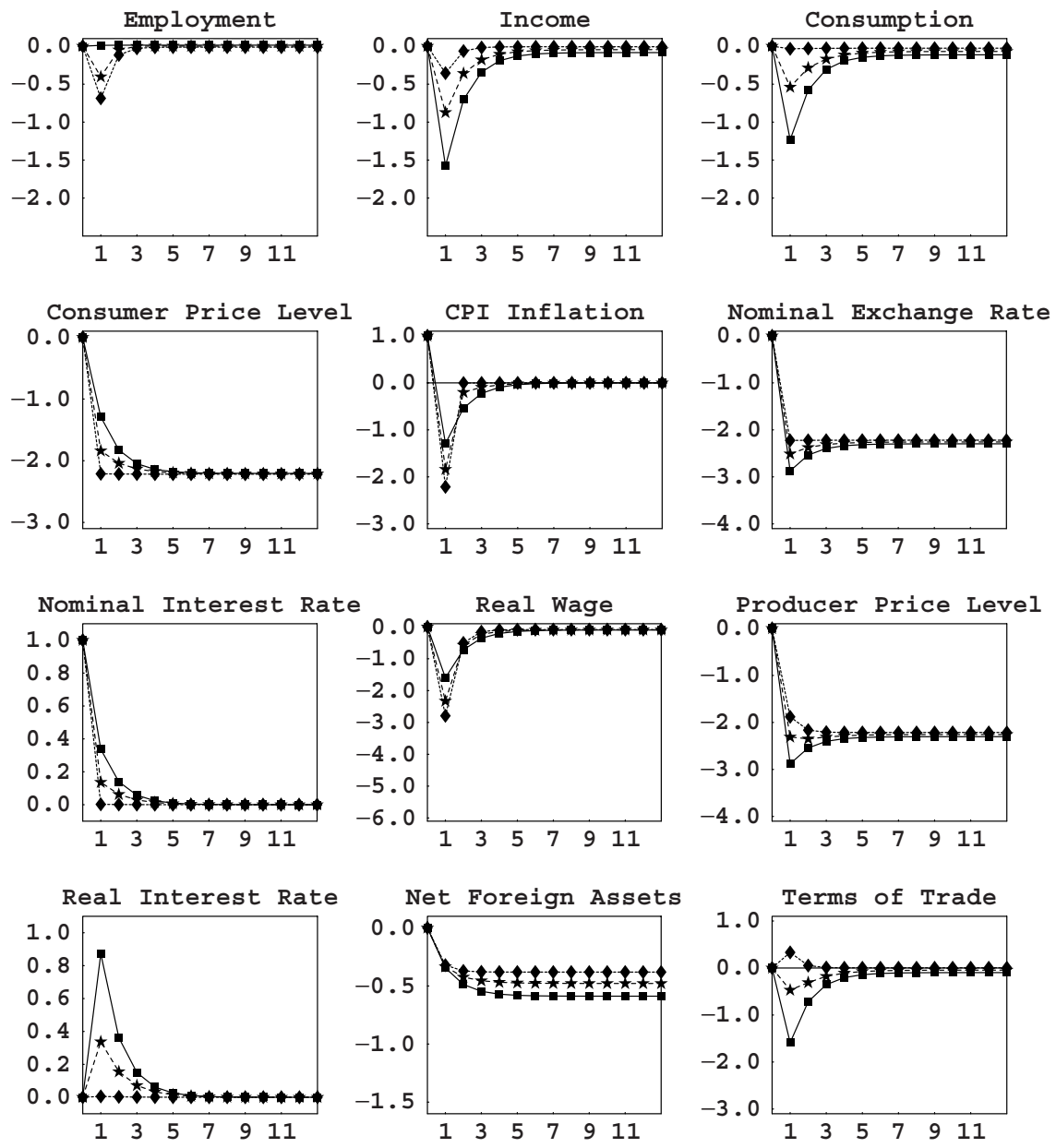

FigURE 2. Effects of lower price inertia. $\mathbf{\square}, s=0$; $\star s=0.5$; and $\diamond, s=1$.

the buyers' currency, the expenditure-switching effect of the monetary slowdown will be diminished. Hence, as the degree of LCP in the economy increases, the contractionary effect of the disinflation on employment will be mitigated. This can be seen in the exchange-rate and employment panels of Figure 1. Moving from higher to lower degrees of pass-through (lower to higher values of $s$ ), it is seen that the overshooting of the exchange rate is greater and the fall in domestic employment is smaller.

The overshooting of the exchange rate can be understood by considering again the impact of disinflation on money demand. Recall that a disinflation implies a fall in the expected inflation rate and the nominal interest rate and therefore a rise in money demand. When there is complete exchange-rate pass-through, money 
market equilibrium is restored by an appreciation in the exchange rate, which produces a fall in the consumer price index and thus a rise in real balances. On the other hand, the presence of incomplete pass-through, that is, firms engaging in LCP, reduces the impact of exchange-rate movements on the overall price level. ${ }^{8}$ This means that exchange rate movements have less effect on the real value of the money supply. Thus, in this case, the exchange rate must move by more in the short run in order to restore money market equilibrium.

A further interesting result seen in Figure 1 is that the response of consumption to the monetary slowdown is more strongly negative, the lower the degree of passthrough. This again can be linked to the adjustments necessary to restore money market equilibrium following the disinflation. As the exchange rate becomes less effective as a means of restoring equilibrium, because of lower pass-through, the role of consumption in restoring money market equilibrium increases. Therefore greater movements in consumption are required for money market equilibrium as the degree of pass-through decreases.

Notice that, even though employment is less affected by a monetary slowdown when there is incomplete pass-through, the impact effect on income increases as pass-through is reduced. This is because the appreciation of the nominal exchange rate causes a fall in the real terms of trade, which reduces the value (in terms of the consumption bundle) of a given volume of home-produced goods. ${ }^{9}$ Notice that, because of consumption smoothing, in the short run, consumption falls by less than income. As in the complete pass-through case, the home country runs down its foreign asset holdings in the short run. ${ }^{10}$

Unlike the complete pass-through case, consumption follows a marked upward trend after the initial fall. This is consistent with the sharp rise in the real interest rate that follows the implementation of the disinflation policy. It also reflects the fact that the consumption adjustment required to restore equilibrium in the money market diminishes as goods prices slowly adjust to the disinflation.

Another contrast with the complete pass-through case is that there is now some degree of sluggishness in the adjustment of CPI inflation to its new steady state. Figure 1 shows that, having overshot in the short run, CPI inflation slowly converges to its new steady state from below. This slow convergence is another consequence of the reduced pass-through that results from LCP behavior. Figure 1 shows that the consumer price level must, regardless of the degree of pass-through, fall by approximately $2 \%$ in the long run in order to restore money market equilibrium. When there is full pass-through, this fall in the CPI can be achieved very quickly through an appreciation of the nominal exchange rate. When there is incomplete pass-through, the exchange rate has less effect on the CPI, so the necessary long-run $2 \%$ adjustment in the level of the CPI requires a prolonged period of negative inflation. ${ }^{11}$

It appears that one of the important implications of incomplete pass-through is that, in contrast to the complete pass-through case, exchange rate overshooting does occur following a disinflation. This is consistent with the results emphasized by Buiter and Miller (1982). However, note that although incomplete pass-through 
implies that the exchange rate responds more to disinflation, employment responds by less. This is not consistent with the results of the previous literature, which emphasized overshooting precisely because it created large output and employment effects of disinflation.

Figure 2 shows the effects of reducing the degree of price inertia also for the incomplete pass-through cases. Notice again that reducing the degree of price inertia reduces the size of the impact effect of the disinflation and increases the speed of adjustment to the new steady state.

\subsection{Extensions}

Another type of disinflation policy that has been more commonly implemented in recent years is one based on a fixed nominal exchange rate. Simulations (not reported) using the above model show that this type of disinflation policy produces a rapid adjustment of inflation with no output or employment costs and with a new steady state reached almost immediately. ${ }^{12}$ In effect, the exchange-rate-based disinflation allows the money supply to be endogenous and thus makes it possible for money market equilibrium to be restored without any need for a decline in the nominal price level. In turn, this eliminates the need for a recession.

For an exchange-rate-based policy, the degree of exchange-rate pass-through makes little difference to the impact of a disinflation. Exchange-rate-based disinflation implies, by definition, that the exchange rate does not change following the implementation of the policy. The main implications of incomplete pass-through arise from its impact on the transmission of nominal exchange-rate movements to the rest of the economy. If there are no movements in the nominal exchange rate, then the presence, or indeed the extent, of pass-through becomes irrelevant.

It must be emphasized, however, that the rapid and painless adjustment of the economy predicted by this model (which is particularly evident following an exchange-rate-based disinflation) is a consequence of the overlapping contracts structure, combined with forward-looking pricing behavior. It is a well-known feature of such pricing models that, when they are used in a closed economy setting, inflation adjustment is very rapid. Fuhrer and Moore (1995) suggest that a more empirically acceptable model allows for some backward-looking element in pricing behavior. An interesting line of future research would be to consider a modified version of the above open-economy model that incorporates backwardlooking behavior of this type. However, it is hard to find convincing microeconomic foundations for backward-looking pricing behavior, and a version of the above open-economy model modified to include such behavior is vulnerable to the same criticisms as the older disinflation literature based on variants of the Dornbusch model.

\section{CONCLUSIONS}

Extensive evidence has revealed the presence of incomplete exchange rate passthrough to be an important empirical feature of most economies. It is therefore 
important to consider the implications of incomplete pass-through in examining the real effects of disinflation policy. This paper analyzes exchange-rate dynamics following a money-based disinflation under different degrees of exchange rate pass-through. Using a microfounded dynamic general equilibrium model, it is shown that a monetary slowdown causes an appreciation of the exchange rate and a short-run fall in employment. Analyzing the effects of disinflation under incomplete pass-through, however, significantly alters the magnitudes of these effects. The extent of the short-run appreciation of the exchange rate is increased and the short-run impact of the disinflation on employment is reduced under lower degrees of pass-through.

\section{NOTES}

1. There is an extensive literature on the disinflation programs of Latin American countries facing high and persistent inflation in the 1970s and 1980s. Calvo and Végh (1999) present a comprehensive survey of this literature. Some of the contributions in this strand of literature have developed models with microfoundations. Another strand of the disinflation literature investigates the implications of the microfoundations of overlapping nominal contracts for the real effects of disinflation [see Ascari and Rankin (2002), for instance]. Nevertheless, in neither of these strands of the literature has there, as yet, been a systematic analysis of the impact of incomplete exchange rate pass-through on money-based disinflation in a model with fully worked out microfoundations.

2. An analysis of the large-country case, where $n=\frac{1}{2}$, has been carried out and produced results that are qualitatively the same as those discussed below.

3. Although the choice of parameter values affects the quantitative impact of disinflation, the qualitative features of the results presented below have been found to be robust across many variations of these parameters. The results of this robustness analysis are available from the author on request.

4. The real wage falls because of the drop in the demand for labor at the start of a disinflation program. A fall in real wages of the magnitude implied by Figure 1 is almost certainly unrealistic.

5. Note that employment depends on the physical volume of production, whereas income depends on the volume of production valued at producer prices relative to consumer prices.

6. It should be noted that this immediate downward adjustment in the consumer price index implies that inflation is negative in the period in which the disinflation is implemented. Thus inflation initially overshoots its new long-run equilibrium value. This overshoot is almost certainly counterfactual. Also note that the analysis of a small open economy (with no home bias in consumption, as is the case here) implies that the share of foreign goods far outweighs the share of home-produced goods in the home consumption bundle. As such, in the case of complete pass-through, the nominal exchange rate has a very large effect on the home country CPI compared to the effects of the price of home-produced goods.

7. In Figure 1 the home producer price level is defined as a weighted average of the prices charged by LCP and PCP firms, expressed in the home currency.

8. Note that, even when all firms are LCP firms (i.e., $s=1$ ), proportion $1-\gamma$ of firms are able to reset prices in the period in which the disinflation policy is implemented. The prices set by these firms are thus able to respond fully to the change in the exchange rate. So, even when $s=1$, there is some degree of pass-through from exchange-rate changes to consumer prices. This is evident in the consumer price level panel in Figure 1.

9. Obstfeld and Rogoff (2000) note that models with pricing-to-market tend to predict that the terms of trade worsen when the exchange rate appreciates following a monetary contraction. They suggest that this is a counterfactual prediction of such models.

10. In addition to showing that LCP behavior causes the nominal exchange rate to overshoot in response to a change in the level of the money supply, Betts and Devereux (2000) show that 
LCP behavior tends to reduce international consumption co-movements and to increase international output co-movements. The policy experiment conducted here is different from the Betts and Devereux policy experiment, and the model used here focuses on a small open economy case, so foreign output and consumption are fixed. Nevertheless, the results reported here are consistent with the Betts and Devereux (2000) results. In the incomplete pass-through case, the heightened response of home country consumption to a disinflation implies that home consumption is less strongly linked to foreign consumption than in the full pass-through case. In addition, the muted response of employment implies that home output (as measured by employment) is more strongly linked to foreign output than in the full pass-through case.

11. This prolonged period of negative CPI inflation occurs despite the slow depreciation of the nominal exchange rate during the transition to the new long-run steady state. The combination of a depreciating currency and negative inflation may appear to be paradoxical. However, it should be borne in mind that the home currency prices of foreign-produced LCP goods are falling during the transition period, as a delayed response to the initial appreciation of the exchange rate.

12. For the purposes of this policy experiment, it is assumed that the exchange rate is fixed at the level it achieves in period 0 . That is, when the disinflation policy is implemented in period 1 , the monetary authority ensures that there is no change in the exchange rate between period 0 and period 1 , and that the exchange rate is fixed at that level thereafter.

\section{REFERENCES}

Ascari, Guido and Neil Rankin (2002) Staggered wages and output dynamics under disinflation. Journal of Economic Dynamics and Control 26, 653-680.

Betts, Caroline and Michael B. Devereux (1996) The exchange rate in a model of pricing-to-market. European Economic Review 40, 1007-1021.

Betts, Caroline and Michael B. Devereux (2000) Exchange rate dynamics in a model of pricing-tomarket. Journal of International Economics 50, 215-244.

Buiter, Willem and Marcus Miller (1981) The Thatcher experiment: The first two years. Brookings Papers on Economic Activity 1981, 315-367.

Buiter, Willem and Marcus Miller (1982) Real exchange rate overshooting and the output cost of bringing down inflation. European Economic Review 18, 85-123.

Buiter, Willem and Marcus Miller (1983) Changing the rules: Economic consequences of the Thatcher regime. Brookings Papers on Economic Activity 1983, 305-379.

Buiter, Willem and Marcus Miller (1985) Costs and benefits of an anti-inflationary policy: Questions and issues. In V. Argy and J. Neville (eds.), Inflation and Unemployment: Theory, Experience and Policy Making, pp. 11-38. London: Allen Unwin.

Calvo, Guillermo A. (1983) Staggered prices in a utility-maximizing framework. Journal of Monetary Economics 12, 383-398.

Calvo, Guillermo A. and Carlos A. Végh (1999) Inflation stabilization and balance of payments crises in developing countries. In J. B. Taylor and M. Woodford (eds.), Handbook of Macroeconomics, Vol. 1C, pp. 1531-1614. Amsterdam: North-Holland.

Dornbusch, Rudiger (1976) Expectations and exchange rate dynamics. Journal of Political Economy 84, 1161-1176.

Engel, Charles (1999) Accounting for US real exchange rate changes. Journal of Political Economy 107, 506-538.

Fuhrer, Jeff and George Moore (1995) Inflation persistence. Quarterly Journal of Economics CX, 127-159.

Goldberg, Penelope K. and Michael M. Knetter (1997) Goods prices and exchange rates: What have we learned? Journal of Economic Literature 35, 1243-1272.

Obstfeld, Maurice and Kenneth Rogoff (1995) Exchange rate dynamics redux. Journal of Political Economy 103, 624-660. 
Obstfeld, Maurice and Kenneth Rogoff (2000) New directions for stochastic open economy models. Journal of International Economics 50, 117-153.

\section{APPENDIX A}

\section{EQUILIBRIUM CONDITIONS}

Equilibrium in the world economy may be described by the following equations:

$$
\begin{aligned}
& C_{t+1}=C_{t}\left[\left(\beta\left(1+i_{t}\right) P_{t}\right) / P_{t+1}\right]^{\sigma}, \\
& C_{t+1}^{*}=C_{t}^{*}\left[\left(\beta\left(1+i_{t}^{*}\right) P_{t}^{*}\right) / P_{t+1}^{*}\right]^{\sigma}, \\
& M_{t} / P_{t}=\left[\chi C_{t}^{1 / \sigma}\left(\left(1+i_{t}\right) / i_{t}\right)\right]^{1 / \epsilon}, \\
& M_{t}^{*} / P_{t}^{*}=\left[\chi C_{t}^{* 1 / \sigma}\left(\left(1+i_{t}^{*}\right) / i_{t}^{*}\right)\right]^{1 / \epsilon}, \\
& N_{t}^{(\mu-1)}=C_{t}^{-1 / \sigma} w_{t} / P_{t}, \\
& N_{t}^{*(\mu-1)}=C_{t}^{*-1 / \sigma} w_{t}^{*} / P_{t}^{*}, \\
& n N_{t}=\int_{0}^{s n}\left[x_{\mathrm{H}, t}(z)+x_{\mathrm{F}, t}(z)\right] d z+\int_{s n}^{n} y_{t}(z) d z, \\
& (1-n) N_{t}^{*}=\int_{n}^{n+(1-n) s}\left[x_{\mathrm{H}, t}^{*}(z)+x_{\mathrm{F}, t}^{*}(z)\right] d z+\int_{n+(1-n) s}^{1} y_{t}^{*}(z) d z, \\
& p_{\mathrm{L}, t}^{\mathrm{N}}(z)(\theta-1) \sum_{\tau=t}^{\infty} \gamma^{\tau-t} R_{t, \tau} \frac{C_{\tau}}{P_{\tau}^{1-\theta}}=\theta \sum_{\tau=t}^{\infty} \gamma^{\tau-t} R_{t, \tau} \frac{C_{\tau}}{P_{\tau}^{1-\theta}} w_{\tau} \text {, } \\
& q_{\mathrm{L}, t}^{\mathrm{N}}(z)(\theta-1) \sum_{\tau=t}^{\infty} \gamma^{\tau-t} R_{t, \tau} \frac{C_{\tau}^{*}}{P_{\tau} P_{\tau}^{*-\theta}} E_{\tau}=\theta \sum_{\tau=t}^{\infty} \gamma^{\tau-t} R_{t, \tau} \frac{C_{\tau}^{*}}{P_{\tau} P_{\tau}^{*-\theta}} w_{\tau}, \\
& p_{\mathrm{P}, t}^{\mathrm{N}}(z)(\theta-1) \sum_{\tau=t}^{\infty} \gamma^{\tau-t} R_{t, \tau}\left(\frac{n C_{\tau}}{P_{\tau}^{1-\theta}}+\frac{(1-n) C_{\tau}^{*}}{P_{\tau}\left(P_{\tau}^{*} E_{\tau}\right)^{-\theta}}\right) \\
& =\theta \sum_{\tau=t}^{\infty} \gamma^{\tau-t} R_{t, \tau}\left(\frac{n C_{\tau}}{P_{\tau}^{1-\theta}}+\frac{(1-n) C_{\tau}^{*}}{P_{\tau}\left(P_{\tau}^{*} E_{\tau}\right)^{-\theta}}\right) w_{\tau} \\
& p_{\mathrm{L}, t}^{* \mathrm{~N}}(z)(\theta-1) \sum_{\tau=t}^{\infty} \gamma^{\tau-t} R_{t, \tau} \frac{C_{\tau}}{E_{\tau} P_{\tau}^{*} P_{\tau}^{-\theta}}=\theta \sum_{\tau=t}^{\infty} \gamma^{\tau-t} R_{t, \tau} \frac{C_{\tau}}{P_{\tau}^{*} P_{\tau}^{-\theta}} w_{\tau}^{*}, \\
& q_{\mathrm{L}, t}^{* \mathrm{~N}}(z)(\theta-1) \sum_{\tau=t}^{\infty} \gamma^{\tau-t} R_{t, \tau} \frac{C_{\tau}^{*}}{P_{\tau}^{* 1-\theta}}=\theta \sum_{\tau=t}^{\infty} \gamma^{\tau-t} R_{t, \tau} \frac{C_{\tau}^{*}}{P_{\tau}^{* 1-\theta}} w_{\tau}^{*},
\end{aligned}
$$




$$
\begin{aligned}
& q_{\mathrm{P}, t}^{* \mathrm{~N}}(z)(\theta-1) \sum_{\tau=t}^{\infty} \gamma^{\tau-t} R_{t, \tau}\left(\frac{n C_{\tau} E_{\tau}^{-\theta}}{P_{\tau}^{*} P_{\tau}^{-\theta}}+\frac{(1-n) C_{\tau}^{*}}{P_{\tau}^{* 1-\theta}}\right) \\
& =\theta \sum_{\tau=t}^{\infty} \gamma^{\tau-t} R_{t, \tau}\left(\frac{n C_{\tau} E_{\tau}^{-\theta}}{P_{\tau}^{*} P_{\tau}^{-\theta}}+\frac{(1-n) C_{\tau}^{*}}{P_{\tau}^{* 1-\theta}}\right) w_{\tau}^{*}, \\
& \left(1+i_{t}\right) E_{t}=\left(1+i_{t}^{*}\right) E_{t+1}, \\
& P_{t} T_{t}=M_{t}-M_{t-1}, \\
& P_{t}^{*} T_{t}^{*}=M_{t}^{*}-M_{t-1}^{*}, \\
& D_{t}=\left(1+i_{t-1}\right) D_{t-1}+M_{t-1}-M_{t}+w_{t} N_{t}-P_{t} C_{t}+\Pi_{t}+P_{t} T_{t} \text {, } \\
& y_{t}(z)=\left[\frac{p_{\mathrm{P}, t}(z)}{P_{t}}\right]^{-\theta} n C_{t}+\left[\frac{p_{\mathrm{P}, t}(z)}{P_{t}^{*} E_{t}}\right]^{-\theta}(1-n) C_{t}^{*}, \\
& y_{t}^{*}(z)=\left[\frac{E_{t} q_{\mathrm{P}, t}^{*}(z)}{P_{t}}\right]^{-\theta} n C_{t}+\left[\frac{q_{\mathrm{P}, t}^{*}(z)}{P_{t}^{*}}\right]^{-\theta}(1-n) C_{t}^{*}, \\
& x_{\mathrm{H}, t}(z)=\left[\frac{p_{\mathrm{L}, t}(z)}{P_{t}}\right]^{-\theta} n C_{t}, \quad x_{\mathrm{F}, t}(z)=\left[\frac{q_{\mathrm{L}, t}(z)}{P_{t}^{*}}\right]^{-\theta}(1-n) C_{t}^{*} \text {, } \\
& x_{\mathrm{H}, t}^{*}(z)=\left[\frac{p_{\mathrm{L}, t}^{*}(z)}{P_{t}}\right]^{-\theta} n C_{t}, \quad x_{\mathrm{F}, t}^{*}(z)=\left[\frac{q_{\mathrm{L}, t}^{*}(z)}{P_{t}^{*}}\right]^{-\theta}(1-n) C_{t}^{*} \text {, } \\
& b_{\mathrm{L}, t}=\left[(1-\gamma) \sum_{\tau=0}^{\infty} \gamma^{\tau} p_{\mathrm{L}, t-\tau}^{\mathrm{N}(1-\theta)}\right]^{1 /(1-\theta)}, \\
& b_{\mathrm{L}, t}^{*}=\left[(1-\gamma) \sum_{\tau=0}^{\infty} \gamma^{\tau} p_{\mathrm{L}, t-\tau}^{* \mathrm{~N}(1-\theta)}\right]^{1 /(1-\theta)} \text {, } \\
& b_{\mathrm{P}, t}=\left[(1-\gamma) \sum_{\tau=0}^{\infty} \gamma^{\tau} p_{\mathrm{P}, t-\tau}^{\mathrm{N}(1-\theta)}\right]^{1 /(1-\theta)} \text {, } \\
& g_{\mathrm{L}, t}=\left[(1-\gamma) \sum_{\tau=0}^{\infty} \gamma^{\tau} q_{\mathrm{L}, t-\tau}^{\mathrm{N}(1-\theta)}\right]^{1 /(1-\theta)} \text {, } \\
& g_{\mathrm{L}, t}^{*}=\left[(1-\gamma) \sum_{\tau=0}^{\infty} \gamma^{\tau} q_{\mathrm{L}, t-\tau}^{* \mathrm{~N}(1-\theta)}\right]^{1 /(1-\theta)} \text {, } \\
& g_{\mathrm{P}, t}^{*}=\left[(1-\gamma) \sum_{\tau=0}^{\infty} \gamma^{\tau} q_{p, t-\tau}^{* \mathrm{~N}(1-\theta)}\right]^{1 /(1-\theta)},
\end{aligned}
$$

Equations (A.1) and (A.2) are the Euler equations for optimal home and foreign consumption growth. Equations (A.3) and (A.4) are the money market clearing conditions. Equations (A.5) and (A.6) clear labor markets in each period, where total demand for home labor is given by (A.7) and total demand for foreign labor is given by (A.8). Equations (A.9) and (A.10) are the optimal-price-setting conditions for home LCP goods, and equation (A.11) 
is the optimal-price-setting condition for home PCP goods. Equations (A.12) and (A.13) are the optimal-price-setting conditions for foreign LCP goods, and equation (A.14) is the optimal-price-setting condition for foreign PCP goods. Equation (A.15) is the uncovered interest parity condition. Equation (A.16) and (A.17) are the government budget constraints. Equation (A.18) is the home-country flow budget constraint, with present discounted values of total consumption in each country being equal to the present discounted values of total labor and profit income. Equations (A.19) and (A.20) represent market-clearing conditions for home and foreign PCP goods. Equations (A.21) and (A.22) represent market-clearing conditions for home and foreign LCP goods. To simplify the notation, equations (A.23) to (A.28) define aggregate price indices for the home and foreign country LCP and PCP goods, where $b_{\mathrm{L}, t}$ represents the aggregate price index for the home-produced LCP good for the home market, $b_{\mathrm{L}, t}^{*}$ represents the aggregate price index for the foreign-produced LCP good for the home market, $b_{\mathrm{P}, t}$ represents the aggregate price index for the home-produced PCP good for the home and the foreign market, $g_{\mathrm{L}, t}$ represents the aggregate price index for the home-produced LCP good for the foreign market, $g_{\mathrm{L}, t}^{*}$ represents the aggregate price index for the foreign-produced LCP good for the foreign market, and $g_{\mathrm{P}, t}^{*}$ represents the aggregate price index for the foreign-produced PCP good for the foreign and the home market.

\section{APPENDIX B}

\section{LOG-LINEARIZED EQUATIONS}

The zero-inflation-zero-debt steady-state values for the real interest rate, the real wage rate, employment, consumption, and real balances are given by the following equations (where a bar indicates the steady state value of a variable):

$$
\begin{gathered}
\bar{r}=\frac{1-\beta}{\beta}, \\
\overline{\bar{P}}=\frac{\theta-1}{\theta}, \\
\bar{N}=\bar{C}=\left[\frac{\theta-1}{\theta}\right]^{\frac{\sigma}{(\mu-1) \sigma+1}}, \\
\frac{\bar{M}}{\bar{P}}=\left[\frac{1-\beta}{\chi}\right]^{1-\epsilon} \bar{y}^{\frac{-1}{\sigma \epsilon}} .
\end{gathered}
$$

Log-linearized versions of the home and foreign households' first-order conditions, that is, equations (B.1) to (B.6), are as follows:

$$
\begin{gathered}
\frac{1}{\sigma}\left(\hat{C}_{t+1}-\hat{C}_{t}\right)=\hat{P}_{t}-\hat{P}_{t+1}+(1-\beta) \hat{l}_{t}, \\
\frac{1}{\sigma}\left(\hat{C}_{t+1}^{*}-\hat{C}_{t}^{*}\right)=\hat{P}_{t}^{*}-\hat{P}_{t+1}^{*}+(1-\beta) \hat{l}_{t}^{*},
\end{gathered}
$$




$$
\begin{gathered}
\hat{M}_{t}-\hat{P}_{t}=\frac{1}{\sigma \epsilon} \hat{C}_{t}-\frac{\beta}{\epsilon} \hat{\imath}_{t}, \\
\hat{M}_{t}^{*}-\hat{P}_{t}^{*}=\frac{1}{\sigma \epsilon} \hat{C}_{t}^{*}-\frac{\beta}{\epsilon} \hat{\imath}_{t}^{*}, \\
\hat{N}_{t}=\frac{1}{\mu-1}\left[\hat{w}_{t}-\hat{P}_{t}-\frac{1}{\sigma} \hat{C}_{t}\right], \\
\hat{N}_{t}^{*}=\frac{1}{\mu-1}\left[\hat{w}_{t}^{*}-\hat{P}_{t}^{*}-\frac{1}{\sigma} \hat{C}_{t}^{*}\right] .
\end{gathered}
$$

Log deviations from the initial equilibrium are indicated by a circumflex.

The log-linearized version of the uncovered-interest-rate parity equation (A.15) is

$$
(1-\beta) \hat{\imath}_{t}=\hat{E}_{t+1}-\hat{E}_{t}+(1-\beta) \hat{\imath}_{t}^{*}
$$

Log-linearized versions of the home LCP firms' two price-setting conditions, given by equations (A.9) and (A.10), and the home PCP firm's price-setting condition, given by equation (A.11), are defined as follows (after simplification):

$$
\begin{aligned}
& \hat{p}_{\mathrm{L}, t}^{\mathrm{N}}=(1-\beta \gamma) \sum_{\tau=t}^{\infty}(\beta \gamma)^{\tau-t} \hat{w}_{\tau}, \\
& \hat{q}_{\mathrm{L}, t}^{\mathrm{N}}=(1-\beta \gamma) \sum_{\tau=t}^{\infty}(\beta \gamma)^{\tau-t}\left[\hat{w}_{\tau}-\hat{E}_{\tau}\right], \\
& \hat{p}_{\mathrm{P}, t}^{\mathrm{N}}=(1-\beta \gamma) \sum_{\tau=t}^{\infty}(\beta \gamma)^{\tau-t} \hat{w}_{\tau} .
\end{aligned}
$$

Note that all LCP firms that have the opportunity to change their prices in period $t$ set their prices to $\hat{p}_{\mathrm{L}, t}^{\mathrm{N}}$ and $\hat{q}_{\mathrm{L}, t}^{\mathrm{N}}$ and all PCP firms that have the opportunity to change their price in period $t$ set their price to $\hat{p}_{\mathrm{P}, t}^{\mathrm{N}}$. Thus, $\hat{p}_{\mathrm{L}, t}^{\mathrm{N}}, \hat{q}_{\mathrm{L}, t}^{\mathrm{N}}$, and $\hat{p}_{\mathrm{P}, t}^{\mathrm{N}}$ represent the prices of all firms that reset prices in period $t$.

The log-linearized versions of the foreign LCP firms' two price-setting conditions, equations (A.12) and (A.13), and the foreign PCP firm's price-setting condition, equation (A.14), are defined as follows (after simplification):

$$
\begin{aligned}
& \hat{p}_{\mathrm{L}, t}^{* \mathrm{~N}}=(1-\beta \gamma) \sum_{\tau=t}^{\infty}(\beta \gamma)^{\tau-t}\left[\hat{w}_{\tau}^{*}+\hat{E}_{\tau}\right], \\
& \hat{q}_{\mathrm{L}, t}^{* \mathrm{~N}}=(1-\beta \gamma) \sum_{\tau=t}^{\infty}(\beta \gamma)^{\tau-t} \hat{w}_{\tau}^{*} \\
& \hat{q}_{\mathrm{P}, t}^{* \mathrm{~N}}=(1-\beta \gamma) \sum_{\tau=t}^{\infty}(\beta \gamma)^{\tau-t} \hat{w}_{\tau}^{*}
\end{aligned}
$$

Again, $\hat{p}_{\mathrm{L}, t}^{* \mathrm{~N}}, \hat{q}_{\mathrm{L}, t}^{* \mathrm{~N}}$, and $\hat{q}_{\mathrm{P}, t}^{* \mathrm{~N}}$ represent the prices of all firms that reset prices in period $t$. 
It is possible to rewrite equations (B.12)-(B.17) as first-order difference equations of the following form:

$$
\begin{aligned}
& \hat{p}_{\mathrm{L}, t}^{\mathrm{N}}=(1-\beta \gamma) \hat{w}_{t}+\beta \gamma \hat{p}_{\mathrm{L}, t+1}^{\mathrm{N}}, \\
& \hat{q}_{\mathrm{L}, t}^{\mathrm{N}}=(1-\beta \gamma)\left(\hat{w}_{t}-\hat{E}_{t}\right)+\beta \gamma \hat{q}_{\mathrm{L}, t+1}^{\mathrm{N}}, \\
& \hat{q}_{\mathrm{P}, t}^{\mathrm{N}}=(1-\beta \gamma) \hat{w}_{t}+\beta \gamma \hat{q}_{\mathrm{P}, t+1}^{\mathrm{N}}, \\
& \hat{p}_{\mathrm{L}, t}^{* \mathrm{~N}}=(1-\beta \gamma)\left(\hat{w}_{t}^{*}+\hat{E}_{t}\right)+\beta \gamma \hat{p}_{\mathrm{L}, t+1}^{* \mathrm{~N}}, \\
& \hat{q}_{\mathrm{L}, t}^{* \mathrm{~N}}=(1-\beta \gamma) \hat{w}_{t}^{*}+\beta \gamma \hat{q}_{\mathrm{L}, t+1}^{* \mathrm{~N}}, \\
& \hat{q}_{\mathrm{P}, t}^{* \mathrm{~N}}=(1-\beta \gamma) \hat{w}_{t}^{*}+\beta \gamma \hat{q}_{\mathrm{P}, t+1}^{* \mathrm{~N}} .
\end{aligned}
$$

In order to simplify the notation, aggregate price indices for the home and foreign country LCP and PCP goods are defined as

$$
\begin{aligned}
& b_{\mathrm{L}, t}=\left[(1-\gamma) \sum_{\tau=0}^{\infty} \gamma^{\tau} p_{\mathrm{L}, t-\tau}^{\mathrm{N}(1-\theta)}\right]^{1 /(1-\theta)}, \\
& b_{\mathrm{L}, t}^{*}=\left[(1-\gamma) \sum_{\tau=0}^{\infty} \gamma^{\tau} p_{\mathrm{L}, t-\tau}^{* \mathrm{~N}(1-\theta)}\right]^{1 /(1-\theta)}, \\
& b_{\mathrm{P}, t}=\left[(1-\gamma) \sum_{\tau=0}^{\infty} \gamma^{\tau} p_{\mathrm{P}, t-\tau}^{\mathrm{N}(1-\theta)}\right]^{1 /(1-\theta)}, \\
& g_{\mathrm{L}, t}=\left[(1-\gamma) \sum_{\tau=0}^{\infty} \gamma^{\tau} q_{\mathrm{L}, t-\tau}^{\mathrm{N}(1-\theta)}\right]^{1 /(1-\theta)}, \\
& g_{\mathrm{L}, t}^{*}=\left[(1-\gamma) \sum_{\tau=0}^{\infty} \gamma^{\tau} q_{\mathrm{L}, t-\tau}^{* \mathrm{~N}(1-\theta)}\right]^{1 /(1-\theta)}, \\
& g_{\mathrm{P}, t}^{*}=\left[(1-\gamma) \sum_{\tau=0}^{\infty} \gamma^{\tau} q_{p, t-\tau}^{* \mathrm{~N}(1-\theta)}\right]^{1 /(1-\theta)},
\end{aligned}
$$

where $b_{\mathrm{L}, t}$ represents the aggregate price index for the home-produced LCP good for the home market, $b_{\mathrm{L}, t}^{*}$ represents the aggregate price index for the foreign-produced LCP good for the home market, $b_{\mathrm{P}, t}$ represents the aggregate price index for the home-produced PCP good for the home and the foreign market, $g_{\mathrm{L}, t}$ represents the aggregate price index for the home-produced LCP good for the foreign market, $g_{\mathrm{L}, t}^{*}$ represents the aggregate price index for the foreign-produced LCP good for the foreign market, and $g_{\mathrm{P}, t}^{*}$ represents the aggregate price index for the foreign-produced PCP good for the foreign and the home market. These equations can be log-linearized and written in the form of first-order difference equations as follows:

$$
\begin{aligned}
& \hat{b}_{\mathrm{L}, t}=\gamma \hat{b}_{\mathrm{L}, t-1}+(1-\gamma) \hat{p}_{\mathrm{L}, t}^{\mathrm{N}} \\
& \hat{b}_{\mathrm{L}, t}^{*}=\gamma \hat{b}_{\mathrm{L}, t-1}+(1-\gamma) \hat{p}_{\mathrm{L}, t}^{* \mathrm{~N}}
\end{aligned}
$$




$$
\begin{aligned}
& \hat{b}_{\mathrm{P}, t}=\gamma \hat{b}_{\mathrm{P}, t-1}+(1-\gamma) \hat{p}_{\mathrm{P}, t}^{\mathrm{N}} \\
& \hat{g}_{\mathrm{L}, t}=\gamma \hat{g}_{\mathrm{L}, t-1}+(1-\gamma) \hat{q}_{\mathrm{L}, t}^{\mathrm{N}} \\
& \hat{g}_{\mathrm{L}, t}^{*}=\gamma \hat{g}_{\mathrm{L}, t-1}^{*}+(1-\gamma) \hat{q}_{\mathrm{L}, t}^{* \mathrm{~N}} \\
& \hat{g}_{\mathrm{P}, t}^{*}=\gamma \hat{g}_{\mathrm{P}, t-1}^{*}+(1-\gamma) \hat{q}_{\mathrm{P}, t}^{* \mathrm{~N}} .
\end{aligned}
$$

Note, from equations (B.12), (B.14) and (B.24), (B.26) and equations (B.16), (B.17) and (B.28), (B.29), that

$$
\hat{b}_{\mathrm{L}, t}=\hat{b}_{\mathrm{P}, t}
$$

and

$$
\hat{g}_{\mathrm{L}, t}^{*}=\hat{g}_{\mathrm{P}, t}^{*} \text {. }
$$

The consumer price index (2) for the home economy may now be rewritten as

$$
\begin{aligned}
P_{t} & =\left\{n s\left(b_{\mathrm{L}, t}\right)^{1-\theta}+n(1-s)\left(b_{\mathrm{P}, t}\right)^{1-\theta}+[(1-n) s]\left(b_{\mathrm{L}, t}^{*}\right)^{1-\theta}\right. \\
& \left.+[1-(n+(1-n) s)]\left(E_{t} g_{\mathrm{P}, t}^{*}\right)^{1-\theta}\right\}^{1 /(1-\theta)} .
\end{aligned}
$$

The log-linearized version of this is

$$
\hat{P}_{t}=n s \hat{b}_{\mathrm{L}, t}+n(1-s) \hat{b}_{\mathrm{P}, t}+((1-n) s) \hat{b}_{\mathrm{L}, t}^{*}+(1-(n+(1-n) s))\left(\hat{E}_{t}+\hat{g}_{\mathrm{P}, t}^{*}\right)
$$

given that $\hat{b}_{\mathrm{L}, t}=\hat{b}_{\mathrm{P}, t}$, it is possible to rewrite this as

$$
\hat{P}_{t}=n \hat{b}_{\mathrm{P}, t}+((1-n) s) \hat{b}_{\mathrm{L}, t}^{*}+(1-(n+(1-n) s))\left(\hat{E}_{t}+\hat{g}_{\mathrm{P}, t}^{*}\right) .
$$

The consumer price index for the foreign economy may also be written as

$$
\begin{aligned}
& P_{t}^{*}=\left\{n s\left(g_{\mathrm{L}, t}\right)^{1-\theta}+n(1-s)\left(b_{\mathrm{P}, t} / E_{t}\right)^{1-\theta}+[(1-n) s]\left(g_{\mathrm{L}, t}^{*}\right)^{1-\theta}\right. \\
& \left.\quad+[1-(n+(1-n) s)]\left(g_{\mathrm{P}, t}^{*}\right)^{1-\theta}\right\}^{1 /(1-\theta)} .
\end{aligned}
$$

The loglinearized version of this is

$$
\hat{P}_{t}^{*}=n s \hat{g}_{\mathrm{L}, t}+n(1-s)\left(\hat{b}_{\mathrm{P}, t}-\hat{E}_{t}\right)+((1-n) s) \hat{g}_{\mathrm{L}, t}^{*}+(1-(n+(1-n) s))\left(\hat{g}_{\mathrm{P}, t}^{*}\right) ;
$$

given that $\hat{g}_{\mathrm{L}, t}^{*}=\hat{g}_{\mathrm{P}, t}^{*}$, it is possible to rewrite this as

$$
\hat{P}_{t}^{*}=n s \hat{g}_{\mathrm{P}, t}+n(1-s)\left(\hat{b}_{\mathrm{P}, t}-\hat{E}_{t}\right)+(1-n) \hat{g}_{\mathrm{P}, t}^{*} .
$$

The output of home LCP firms for the home and the foreign market is given by (A.21) and can be log-linearized and written as follows:

$$
\begin{aligned}
& \hat{x}_{\mathrm{H}, t}=\hat{C}_{t}-\theta\left(\hat{b}_{\mathrm{L}, t}-\hat{P}_{t}\right) \\
& \hat{x}_{\mathrm{F}, t}=\hat{C}_{t}^{*}-\theta\left(\hat{g}_{\mathrm{L}, t}-\hat{P}_{t}^{*}\right) .
\end{aligned}
$$

The output of home PCP firms for the home and the foreign market is given by equation (A.19) and can be log-linearized and written as follows:

$$
\hat{y}_{t}=n\left[\hat{C}_{t}-\theta\left(\hat{b}_{\mathrm{P}, t}-\hat{P}_{t}\right)\right]+(1-n)\left[\hat{C}_{t}^{*}-\theta\left(\hat{b}_{\mathrm{P}, t}-\hat{E}_{t}-\hat{P}_{t}^{*}\right)\right] .
$$


The output of foreign LCP firms for the home and the foreign market is given by (A.22) and can be log-linearized and written as follows:

$$
\begin{aligned}
& \hat{x}_{\mathrm{H}, t}^{*}=\hat{C}_{t}-\theta\left(\hat{b}_{\mathrm{L}, t}^{*}-\hat{P}_{t}\right) \\
& \hat{x}_{\mathrm{F}, t}^{*}=\hat{C}_{t}^{*}-\theta\left(\hat{g}_{\mathrm{L}, t}^{*}-\hat{P}_{t}^{*}\right) .
\end{aligned}
$$

The output of foreign PCP firms for the home and the foreign market is given by equation (A.20) and can be log-linearized and written as follows:

$$
\hat{y}_{t}^{*}=n\left[\hat{C}_{t}-\theta\left(\hat{g}_{\mathrm{P}, t}^{*}+\hat{E}_{t}-\hat{P}_{t}\right)\right]+(1-n)\left[\hat{C}_{t}^{*}-\theta\left(\hat{g}_{\mathrm{P}, t}^{*}-\hat{P}_{t}^{*}\right)\right] .
$$

Log-linear equations for the labor-market clearing of the home and foreign economies, respectively, are as follows:

$$
\begin{aligned}
& \hat{N}_{t}=s\left[n \hat{x}_{\mathrm{H}, t}+(1-n) \hat{x}_{\mathrm{F}, t}\right]+(1-s) \hat{y}_{t} \\
& \hat{N}_{t}^{*}=s\left[n \hat{x}_{\mathrm{H}, t}^{*}+(1-n) \hat{x}_{\mathrm{F}, t}^{*}\right]+(1-s) \hat{y}_{t}^{*} .
\end{aligned}
$$

Log-linearizing the budget constraint, equation (A.18), leads to

$$
\begin{aligned}
& \hat{D}_{t}=\frac{1}{\beta} \hat{D}_{t-1}-\hat{C}_{t}-\hat{P}_{t}+s\left[n \hat{x}_{\mathrm{H}, t}+(1-n) \hat{x}_{\mathrm{F}, t}\right]+(1-s) \hat{y}_{t} \\
& \quad+s\left[n \hat{b}_{\mathrm{L}, t}+(1-n)\left(\hat{g}_{\mathrm{L}, t}+\hat{E}_{t}\right)\right]+(1-s) \hat{b}_{\mathrm{P}, t},
\end{aligned}
$$

where $\hat{D}$ is defined as $D / \bar{C}$ (since the steady-state value of this variable is zero, a log deviation is not defined).

These equations form a system of equations that can be solved to yield deterministic solution paths for all the variables of the model. The system can be written in terms of 28 equations in 28 unknowns: $\left\{\hat{b}_{\mathrm{L}, t}, \hat{b}_{\mathrm{L}, t}^{*}, \hat{g}_{\mathrm{L}, t}, \hat{g}_{\mathrm{L}, t}^{*}, \hat{D}_{t}, \hat{p}_{\mathrm{L}, t}^{\mathrm{N}}, \hat{q}_{\mathrm{L}, t}^{\mathrm{N}}, \hat{p}_{\mathrm{L}, t}^{* \mathrm{~N}}, \hat{q}_{\mathrm{L}, t}^{* \mathrm{~N}}, \hat{E}_{t}, \hat{C}_{t}, \hat{C}_{t}^{*}\right.$, $\left.\hat{w}_{t}, \hat{w}_{t}^{*}, \hat{\imath}_{t}, \hat{\imath}_{t}^{*}, \hat{P}_{t}, \hat{P}_{t}^{*}, \hat{N}_{t}, \hat{N}_{t}^{*}, \hat{b}_{\mathrm{P}, t}, \hat{g}_{\mathrm{P}, t}^{*}, \hat{x}_{\mathrm{H}, t}, \hat{x}_{\mathrm{F}, t}, \hat{x}_{\mathrm{H}, t}^{*}, \hat{x}_{\mathrm{F}, t}^{*}, \hat{y}_{\mathrm{H}, t}, \hat{y}_{\mathrm{F}, t}\right\}$. The equations are (B.30), (B.31), (B.33), (B.34), (B.52), (B.18), (B.19), (B.21), (B.22), (B.11), (B.5), (B.6), (B.9), (B.10), (B.7), (B.8), (B.40), (B.43), (B.50), (B.51), (B.32), (B.35), (B.44), (B.45), (B.47), (B.48), (B.46), and (B.49). The system can be reduced to a set of 12 first-order difference equations in 12 unknowns. There are 5 predetermined variables $\left\{\hat{b}_{\mathrm{L}, t}, \hat{b}_{\mathrm{L}, t}^{*}, \hat{g}_{\mathrm{L}, t}\right.$, $\left.\hat{g}_{\mathrm{L}, t}^{*}, \hat{D}_{t}\right\}$ and 7 nonpredetermined variables $\left\{\hat{p}_{\mathrm{L}, t}, \hat{q}_{\mathrm{L}, t}, \hat{p}_{\mathrm{L}, t}^{*}, \hat{q}_{\mathrm{L}, t}^{*}, \hat{E}_{t}, \hat{C}_{t}, \hat{C}_{t}^{*}\right\}$. Note that (B.36) and (B.37) imply that only four of the six aggregate log-linearized prices need to be treated as independent predetermined dynamic variables.

To simulate a disinflation, it is necessary to derive starting values for the predetermined variables based on an initial inflationary steady state. This requires an analysis of the effects of $\alpha$ (the initial rate of inflation) on steady-state values. This is most conveniently achieved by considering an inflationary steady state of the linearized version of the model (i.e., the equations listed in the previous paragraph). These equations can be solved for a steady state where $\hat{M}_{t+1}=\left(\hat{M}_{t}+\alpha\right)$ to yield values for $\left\{\hat{b}_{\mathrm{L}, 0}, \hat{b}_{\mathrm{L}, 0}^{*}, \hat{g}_{\mathrm{L}, 0}, \hat{g}_{\mathrm{L}, 0}^{*}\right\}$, where a zero subscript indicates the starting value for a variable. It is assumed that $\hat{M}_{t+1}=\left(\hat{M}_{t}+\alpha\right)$ for $t<0$ and that $\hat{M}_{t}=0$ for $t \geq 0$.

The equations of the model are written as a set of first-order difference equations in state-space form. Numerical values of the eigenvalues and eigenvectors of the transition matrix are calculated and the solution is generated using the set of stable eigenvalues and eigenvectors. 